

\title{
PERCEPÇÃO AMBIENTAL NO ENSINO MÉDIO EM ESCOLA PÚBLICA DE SOLÂNEA- PB
}

\author{
Apresentação: Comunicação Oral
}

Marcilene Santos Silva ${ }^{1}$; Estelita Tayná Medeiros da Silva²; Antônio Cavalcanti da Silva Júnior ${ }^{3}$; Dalvilene Macena da Silva ${ }^{4}$; Gilvaneide Alves de Azeredo ${ }^{5}$

\section{Resumo}

Em meio a tantas preocupações com o planeta, se faz necessário construir um aprendizado sólido, estando este comprometido com as questões ligadas à preservação do ambiente. Diante da falta de capacitação de muitos docentes das escolas públicas em trabalhar esta questão, há a necessidade de inserir a educação ambiental no ambiente escolar, de maneira que todos se mobilizem de forma efetiva para a melhoria da qualidade de vida. Este artigo tem por objetivo fazer um diagnóstico numa escola pública de Solânea, PB sobre esta temática e se a educação ambiental é inserida no projeto político pedagógico da escola. Foram aplicados questionários estruturados com os estudantes do $1^{\circ}$ (primeiro), $2^{\circ}$ (segundo) e $3^{\circ}$ (terceiro) anos do ensino médio, totalizando 134 (cento e trinta e quatro) estudantes. Os resultados indicaram que os conhecimentos dos discentes acerca dos conceitos que envolvem a educação ambiental, estão sendo pouco explorados nas escolas, e tais resultados podem servir de base para desenvolver trabalhos futuros direcionados a esta temática, com a adoção de estratégias e alternativas que possam servir para sensibilizar alunos e professores.

Palavras-Chave: Educação Ambiental, Meio ambiente, Sustentabilidade.

\section{Introdução}

A intensificação e apropriação de recursos naturais pelos meios de produção durante, e após, a revolução industrial, fez com que discussões e preocupações a respeito das questões ambientais começassem a se ampliar. Isto fez com que a problemática ambiental ganhasse grande destaque no cenário mundial, principalmente, na segunda metade do século XX, cuja maior expressão é o

$2{ }^{1}$ Curso de Graduação em Ciências Agrárias, Licenciatura Plena, Centro de Ciências Humanas, Sociais e Agrárias/UFPB, marcilene-1195@hotmail.com

${ }^{2}$ Curso de Graduação em Ciências Agrárias, Licenciatura Plena, CCHSA/UFPB, taynasmedeiros@gmail.com

$3{ }^{3}$ Bacharelado em Zootecnia, Centro de Ciências Agrárias (CCA/UFPB),
cavalcantijunior10@hotmail.com

$4 \quad{ }^{4}$ Licenciada em Pedagogia, CCHSA/UFPB, dalvilenemacena@hotmail.com

${ }^{5}$ Departamento de Agricultura, CCHSA, UFPB, azeredogil@yahoo.com.br 
surgimento do movimento ambientalista. Esse movimento surgiu da crescente consciência social de que, em vez de vida e bem-estar social superiores e apesar de vários benefícios, a industrialização, baseada na ciência e nas tecnologias modernas, provoca doenças e desastres ecológicos, podendo, inclusive, inviabilizar a vida no planeta, pois degrada e polui o meio ambiente.

Na perspectiva de discussão ambiental, o que efetivamente nos preocupa não é a natureza em si, mas os seres humanos que nela habita e continuará a habitar até que a nossa estrela solar continue a existir, segundo FIGUEIRO (2016, p. 80):

"Desenvolver um processo de educação ambiental emancipatório na escola de hoje, capaz de desvelar e fazer frente às estratégias mais atuais do modelo produtivo e cultural que hegemoniza a nossa sociedade, é uma das tarefas mais dificeis e mais desafiadoras para a construção de um futuro em que os seres humanos ainda posam estar ocupando esse planeta com algum grau de humanidade".

A humanidade é que talvez não tenha tempo para adaptar seus modos de vida ao sistema que ele mesmo está produzindo. Pode-se entender que a educação ambiental é um processo pelo qual o homem começa a obter conhecimentos acerca das questões ambientais, onde ele passa a ter uma nova visão sobre o meio ambiente, sendo um agente transformador em relação à conservação ambiental. No entanto há nesse processo três elementos e desafios brutais a serem superados: um desafio ético, teórico metodológico e um desafio político (FIGUEIRO, 2016, p. 80).

Tal como dizia Paulo Freire, "Conhecer, que é sempre um processo, supõe uma situação dialógica". Não há um estritamente falando um "eu penso", mas uns "nós pensamos". Não éo "eu penso" o que constitui o "nós pensamos", mas pelo contrário, é o "nós pensamos" que me faz possível pensar (FREIRE, 1981, p. 71). Assim, educar sobre o que é o homem e como ele se constitui coletivamente, é a primeira das tarefas da Educação Ambiental.

A escola, enquanto espaço de construção de conhecimentos e de um "novo homem", precisa oportunizar essa experiência revolucionária e radical da socialização e dimensão emocional nos seus currículos. É preciso recuperar a capacidade de viver em um mundo sem considerarmos donos dele, pelo contrário, precisamos compreender que devemos nossa existência a existência do outro.

Há diferentes formas de incluir a temática ambiental nos currículos escolares, como as atividades artísticas, experiências práticas, atividades fora da sala de aula, produção de materiais locais, projetos ou qualquer outra atividade que conduza os alunos a serem reconhecidos como agentes ativos no processo que norteia a política ambientalista. Cabe ao professor, por intermédio de práticas interdisciplinares, propor novas metodologias que forneçam a implementação da Educação Ambiental, sempre considerando o ambiente imediato, relacionado a exemplos de problemas ambientais atualizados (SATO, 2004, p. 25).

Muitas vezes, a educação ambiental é compreendida como um conjunto de informações sobre o ambiente como se, o simples acúmulo de conhecimento fosse capaz de transformar as atitudes dos indivíduos. Mais que isso, é preciso compreender que ninguém se educa apenas pelo cognitivo, especialmente quando se busca uma educação que recria as pontes de ligação com as demais dimensões da vida. É preciso que os princípios conceituais da educação Ambiental em si sejam envolvidos em uma ética de transformação libertadora. Cabe a os educadores comprometidos organizar a prática de educar no sentido de potencializar o papel de transformação interna e externa tornando-a efetivamente um instrumento político. 
O objetivo deste trabalho foi desenvolver uma pesquisa que se enquadra numa abordagem quantitativa com o intuito de diagnosticar a percepção dos estudantes de uma escola pública de Solânea, PB sobre a temática educação ambiental no seu contexto escolar.

\section{Metodologia}

Este trabalho foi desenvolvido em uma escola da rede pública estadual, de ensino fundamental e médio na cidade de Solânea-PB. Foi realizado durante o período 2015.2 como parte da disciplina de Ecologia e Meio Ambiente do Curso de Licenciatura em Ciências Agrárias, da Universidade Federal da Paraíba, Centro de Ciências Humanas, Sociais e a Agrárias, CCHSA/UFPB.

Inicialmente, foi elaborado um questionário estruturado com a participação dos discentes da disciplina a fim de investigar a percepção dos alunos em relação a esta temática e se a escola insere este tema no seu projeto pedagógico. Em seguida, foi feita a aplicação dos questionários com os estudantes do $1^{\circ}$ (primeiro), $2^{\circ}$ (segundo) e $3^{\circ}$ (terceiro) anos do ensino médio, totalizando 134 (cento e trinta e quatro) estudantes.

Essa categoria de estudantes foi escolhida pelo motivo de estarem em anos finais de ensino básico e em função de serem os futuros estudantes de graduações. Portanto, é preciso amadurecer a percepção dos mesmos em relação a sensibilização de práticas que gerem sustentabilidade.

\section{Resultados e Discussão}

Desde muitas décadas e até os dias atuais a educação brasileira se depara com desafios, principalmente quando se trata do trabalho com o tema Educação Ambiental. Segundo os parâmetros curriculares nacionais de meio ambiente e saúde, a principal função do trabalho com esse tema é contribuir para a formação de cidadãos conscientes, aptos para decidirem e atuarem na realidade socioambiental de um modo comprometido com a vida, com o bem estar de cada um e da sociedade local e global.

Na prática, vemos uma enorme necessidade de inserir essa temática nos currículos dos estudantes do ensino fundamental e médio até mesmo de forma interdisciplinar.

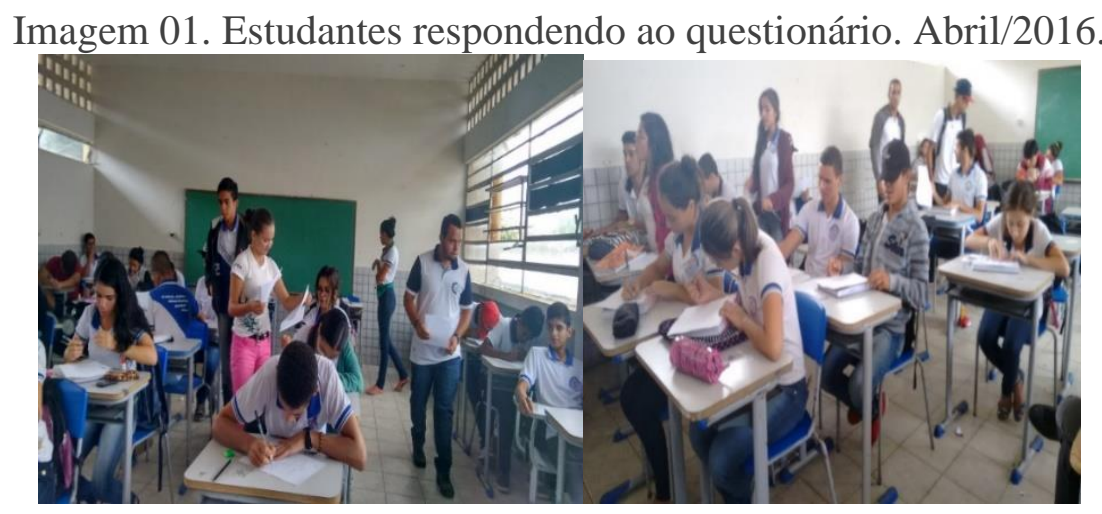

Quando foi perguntado aos estudantes envolvidos na pesquisa se na escola onde estudam tem alguma disciplina que fale sobre a temática educação ambiental, $76 \%$ dos entrevistados responderam que não, o que nos mostrou claramente a dificuldade que os professores têm em trabalhar a temática em aula disciplinar. Esses dados concordam com os de REIGOTA (1994), Parâmetros Curriculares de Santa Catarina (1998) e SATO (2004), de que a Educação Ambiental deve ser trabalhada de modo transversal, contínua e permanente em todas as disciplinas. O restante 
(14\%) respondeu que sim, afirmando que vêem a temática em disciplinas de Biologia e Geografia. BARCELOS (2008, p. 46) comenta, a respeito deste assunto, que a Educação Ambiental não é uma área que deve ser restrita aos professores de Ciências, Biologia ou de Geografia, mas aos professores de todas as disciplinas, ou seja, todos devem trabalhar esse tema. E cerca $10 \%$ dos entrevistados não responderam a questão (Gráfico 1)

\section{Você estuda alguma disciplina que fale da Educação Ambiental?}

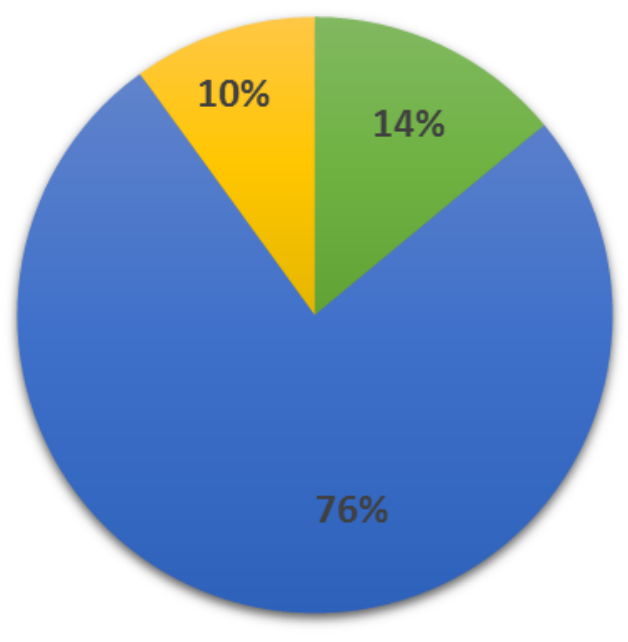

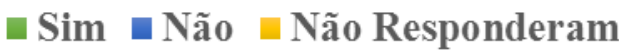

Vimos que é necessário um trabalho extracurricular na escola que vá além de conceitos sociais, mas que envolva ações de mudanças de atitudes, e o papel dos educadores e professores são essenciais nesse processo para impulsionar as transformações de uma educação que assuma um compromisso com a formação de uma visão crítica, de valores e de uma ética para a construção de uma sociedade ambientalmente sustentável (JACOBI ,2005, p. 15).

Quando perguntamos aos estudantes envolvidos na pesquisa se eles já haviam ouvido falar da temática educação ambiental, $48 \%$ dos estudantes (gráfico 2) responderam que não, o que nos faz afirmar mais uma vez que é necessário não apenas conceitos, mas uma formação crítica que envolva ações de conduta e mudanças de atitude dos envolvidos já que estamos lidando com alunos de ensino médio.

2. Você já ouviu falar sobre Educação Ambiental?

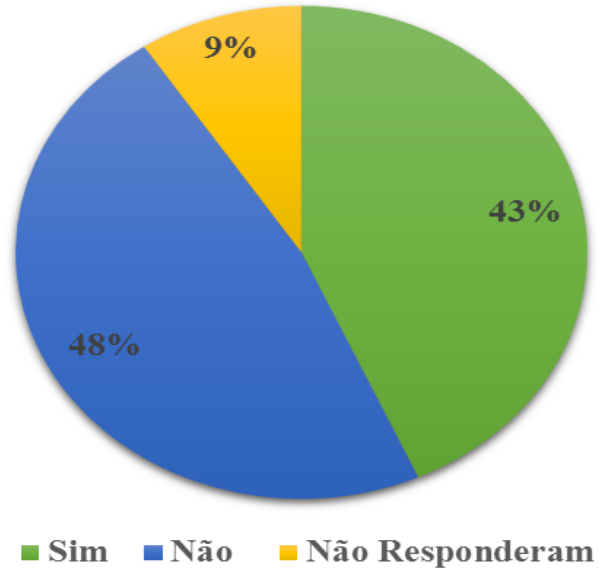


Segundo RUSCHEINSKY (2002, p. 85), a educação ambiental certamente só será possível ser for realizada por uma equipe que discuta e reinvente permanentemente o processo educativo, para que os objetivos buscados sejam construídos. É necessária uma transformação dinâmica, humanista, dialógica e prática na pedagogia da escola envolvida na pesquisa, pois além de não trabalhar com o tema educação ambiental, a escola também não desenvolve trabalhos voltados para a prática ambiental que envolva todos os sujeitos do ambiente escolar. Este dado foi percebido no gráfico 3, quando foi perguntado se os educandos envolvidos participavam de alguma prática de educação ambiental na escola e cerca de $71 \%$, responderam que não. Isto mostra um desafio a ser enfrentado e que talvez não seja apenas dessa escola, mas de diversas escolas brasileiras, visto a necessidade dessas práticas para a construção crítica dos adolescentes que serão nossos futuros profissionais e universitários, seguindo um paradigma convencional e alienado.

"O desafio de um projeto de educação ambiental é incentivar as pessoas a se reconhecerem capazes de tomar atitudes" (MEIRELLES; SANTO, 2005, pg.35).

\section{Você participa de alguma prática de Educação Ambiental na Escola?}



@ Sim $\square$ Não $\square$ Não Responderam

Percebemos que, além de um paradigma emergente a toda uma sociedade brasileira, o trabalho com o tema educação ambiental é de extrema necessidade nos currículos escolares, não só em uma categoria infantil, mas em todos os níveis de ensino, visto a carência de informação que esses sujeitos têm.

Perguntamos aos estudantes onde eles tinham o hábito de jogar lixo, e 51\% responderam nas lixeiras (Gráfico 4), porém, quando se questionou se eles sabiam o que era coleta seletiva de lixo, $38 \%$ dos discentes respondeu que não sabiam (Gráfico 5).

É necessário que os estudantes não apenas joguem o lixo no lixo, mas que despertem a consciência de reaproveitar, reutilizar e reciclar. Dentre os benefícios que resultam da coleta de material reciclável, além da geração de renda para os trabalhadores envolvidos, pode-se citar: a contribuição à saúde pública e ao sistema de saneamento; o fornecimento de material reciclável de baixo custo à indústria; a redução nos gastos municipais e a contribuição à sustentabilidade do meio ambiente, tanto pela diminuição de matéria-prima primária utilizada, que conserva recursos e energia, como pela diminuição da necessidade de terrenos a serem utilizados como lixões e aterros sanitários. 
4. Onde você tem o hábito de jogar lixo?



5. Você sabe o que é coleta seletiva?

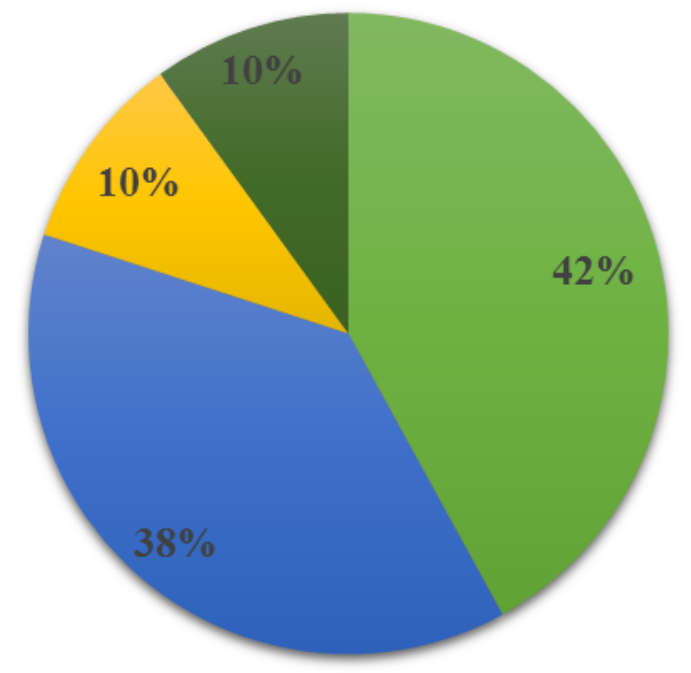

¿ Sim $\square$ Não $\square$ Faz Coleta Seletiva $\square$ Não Faz Coleta seletiva

Cuidar do ambiente é tarefa diária de todos. Ao final de cada dia, devemos ter dado nossa contribuição, além de nos informarmos sobre as questões ambientais - isto é cidadania (DIAS, 2000). A partir desta questão, várias outras se desdobram como, por exemplo: constatamos que o maior problema ambiental encontrado por esses estudantes nos ambientes "rua, casa e escola" são: lixos na rua $(77 \%)$, falta de coleta seletiva $(6 \%)$, desmatamento e queimadas $(7 \%)$, falta de educação (4\%) e (6\%) não responderam (Gráfico 6). 


\section{Quais os problemas ambientais que você encontra nas ruas,}

em casa e na escola?

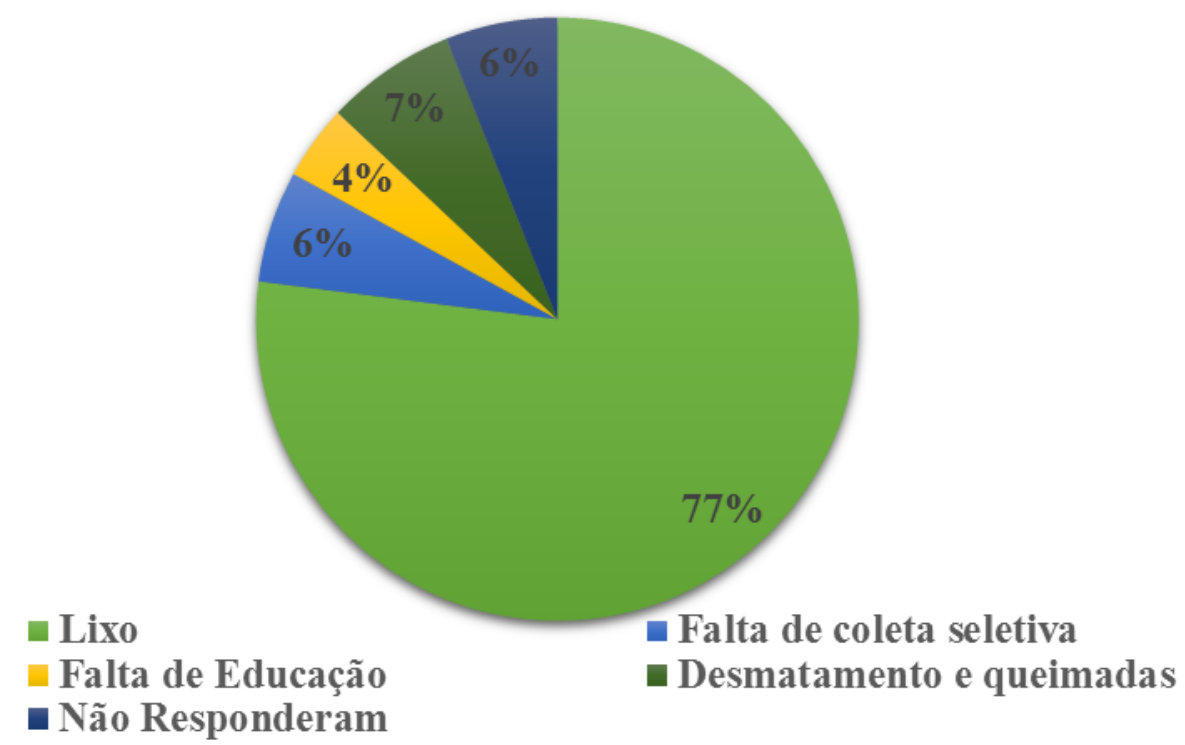

ZEPPONE (1999) desenvolveram um trabalho sobre educação ambiental e o lixo foi citado pelos alunos como o principal problema ambiental.

Segundo DIAS (1992), o lixo é um dos maiores problemas encontrados nas cidades brasileiras, os governantes têm investido "pesadamente" em sistemas de equacionamento do lixo e quem mais sofre com os impactos causados pelo lixo é a comunidade. O lixo é citado como um dos maiores problemas ambientais na comunidade e, consequentemente, está ligado a escola, por ser um ambiente que produz grande quantidade lixo, e pela importância que a instituição escolar tem na formação de cidadãos mais responsáveis e conscientes.

Os estudantes envolvidos nesta pesquisa apontaram que os responsáveis por todos os problemas ambientais descritos por eles é a própria população, e apenas ela poderá amenizar essa problemática (gráfico 7). Perguntou-se aos discentes quem é o responsável por solucionar os problemas ambientais dos seus municípios. Do total, $52 \%$ responderam que é a própria população, $23 \%$ ainda têm uma mentalidade de que os garis e o governo têm essa responsabilidade, $9 \%$ a prefeitura, apenas $7 \%$ disseram que é a educação e $9 \%$ não responderam. FOSCHIERA (2000) tece considerações a respeito, dizendo: "nem químicos, nem biólogos, nem ecólogos podem, sozinhos, encontrar soluções, pois os problemas tornam-se complexos demais; nenhuma área isolada tem conhecimento suficiente para prever soluções, por isso, a busca da interdisciplinaridade".

Machado et al. (2011) desenvolveram um trabalho com a finalidade de diagnosticar a educação ambiental na Escola Estadual Beira Rio, em Porto Nacional, TO, com alunos do Ensino Fundamental de $6^{\circ}$ a $9^{\circ}$ ano, analisando o conhecimento sobre questões ambientais. Observaram que os alunos não têm um conhecimento complexo sobre o meio ambiente, devido a influência da mídia. No entanto, os discentes conhecem métodos que melhoram o meio ambiente, abordada muito bem, na matéria de Ciências e Geografia. 


\section{Quem são os responsáveis para solucionar esses problemas?}

\section{- População \\ - Educação}

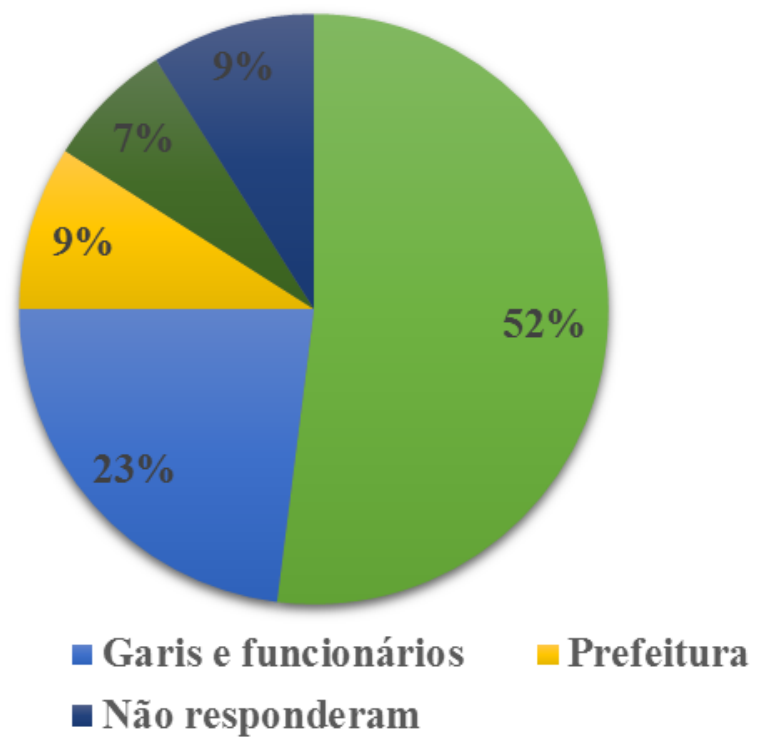

\section{Conclusões}

Conclui-se, de acordo com os resultados obtidos que:

A educação ambiental não é uma prática diária nas escolas. Os alunos não recebem estímulos e a comunidade escolar não oferece o suporte necessário para que os alunos pratiquem, no seu dia-a-dia, novos hábitos que propiciem um ambiente mais saudável;

Existem grandes dificuldades e desafios no ensino médio, no tocante a educação ambiental, e se faz necessário à capacitação de educadores que possam conscientizar os alunos, e articulações de ações educativas para que possam gerar novos conceitos e valores sobre a natureza, contribuindo, assim, para a preservação do meio ambiente.

\section{Referências}

BARCELOS, Valdo. Educação Ambiental - Sobre princípios, metodologias e atitudes. Petrópolis, RJ: Vozes, 2008.

BRASIL. Parâmetros Curriculares Nacionais: Meio Ambiente e Saúde. Ministério da Educação. Secretaria da Educação Fundamental. 3. ed. Brasília: A Secretaria, 2001.

CARVALHO, Isabel Cristina de Moura. Em Direção ao Mundo da Vida: Interdisciplinaridade e Educação Ambiental. Brasília: IPÊ - Instituto de Pesquisas Ecológicas, 1998.

DIAS, Genebaldo F. Educação ambiental. 6.ed. São Paulo: Gaya, 2000.

DIAS, Genebaldo Freire. Educação Ambiental: Princípios e Práticas. $3^{\text {a }}$ ed. São Paulo; Gaia, 1992.

FIGUEIRO, A.S. Educação Ambiental- O capital Natural na Economia Global/ A Educação Ambiental Como Estratégia Para a Criação de Uma Cidadania Global, 2016 p. 80. 
FOSCHIERA, Elisabeth Maria. Educação Ambiental e desenvolvimento - As implicações pedagógicas do projeto Pró-Guaíba na Escola - Polo- 2. Passo Fundo. Passo Fundo. 2000.

FREIRE, P. Ação cultural para a liberdade. E outros escritos. Rio de Janeiro: Paz e Terra, 1981.

JACOBI, Pedro Roberto. Educação Ambiental: o desafio da construção de um pensamento crítico, complexo e reflexivo. Educação e Pesquisa, São Paulo, v.31, n.2, maio/agosto. 2005. Disponível em: www.scielo.com.br. Acesso em: 05 de junho de 2016.

MACHADO, Adinan Souza; GONÇALVES, Dannilo Martins; CARDOSO, Jaina Rodrigues; WEISS, Valeria Adalina Benetti; SANTOS, Alexandre Barreto dos Santos. Educação ambiental de $6^{\circ}$ a $9^{\circ}$ ano: um estudo na Escola Estadual Beira Rio do Distrito de Luzimangues Porto Nacional TO. In: Jornada de Iniciação Científica e Jornada de Extensão da Faculdade Católica do Tocantins, Palmas, p.26-27, 2011.

MEIRELLES, Maria de Sousa; SANTOS, Marly Terezinha. Educação Ambiental uma Construção Participativa. $2^{\text {a }}$ ed. São Paulo, 2005.

REIGOTA, Marcos. O que é educação ambiental? 1. Ed. São Paulo: Editora Brasiliense, 1994.

RUSCHEINSKI, Aloísio. Educação Ambiental - Abordagens Múltiplas. 1 Ed. Porto Alegre: Editora Artmed. 2002.

Parâmetros curriculares de Santa Catarina. Secretaria de Estado da Educação e do Desporto. Proposta curricular de Santa Catarina: educação infantil, ensino fundamental, ensino médio (temas multidisciplinares). Florianópolis: COGEN, 1998.

SATO, Michéle (org.). Educação Ambiental: Pesquisas e Desafios. Porto Alegre: Editora Artmed, 2005. Educação Ambiental. São Carlos: Editora Rima, 2004.

ZEPPONE, Rosimeire. Educação Ambiental: Teorias e Práticas Escolares. 1a ed. São Paulo. Jm, 